\title{
Implantable and Wearable Bionics
}

\author{
N. Lovell \\ Graduate School of Biomedical Engineering, University of New South Wales, Sydney, Australia
}

Abstract- The role of telemetry and communications technology will be explored in a number of medical devices developed at the Graduate School of Biomedical Engineering, University of New South Wales. Topics discussed will include clinical measurement devices used for home telecare, triaxial acceleromters for personal alarming in the elderly, implantable heart pumps and vision prostheses.

In particular, a review of the state-of-art with regards vision neuroprostheses, with an emphasis on retinal prostheses, will be presented. Through an examination of the neurobiology and biophysics at the electrode tissue interface and by drawing heavily on biologicallyinspired designs, critical areas that require concentrated research and development will be described. Brieflycovered are topics relating to application specific integrated circuits (ASIC), appropriate image processing for prosthetic vision, the psychophysics of prosthetic vision, and models of parallel stimulation at multiple electrode sites.

Address of the corresponding author:
$\begin{array}{ll}\text { Author: } & \text { Nigel Lovell } \\ \text { Institute: } & \text { Graduate School of Biomedical Engineering, } \\ & \text { University of New South Wales } \\ \text { City: } & \text { Sydney, NSW 2052 } \\ \text { Country: } & \text { Australia } \\ \text { Email: } & \text { n.lovell@unsw.edu.au }\end{array}$

